\title{
Depression and Quality of Life in Patients With Amyotrophic Lateral Sclerosis
}

\author{
Dorothée Lulé, Sonja Häcker, Albert Ludolph, Niels Birbaumer, Andrea Kübler
}

\begin{abstract}
SUMMARY
Introduction: There is increasing debate on the issue of whether to facilitate the end-of-life decisions of severely disabled patients with diseases such as amyotrophic lateral sclerosis (ALS). Our two studies were intended to explore the emotional state and quality of life of patients with ALS.
\end{abstract}

Methods: Two studies were performed to investigate depression and the quality of life in ALS patients: one was a longitudinal study, the other a comparison of ALS patients to normal control subjects.

Results: These studies found no correlation between physical disability in ALS and either depression or the quality of life. The severity of depression was found to be inversely related to educational status. In ALS patients the quality of life was comparable with healthy controls.

Discussion: The rationale for not providing life-sustaining treatment to severely disabled patients is that a poor quality of life is expected after such treatment. Our studies have shown, however, that ALS patients can experience a satisfactory quality of life without depressive manifestations even if they are severely physically impaired, including in the terminal phase.

Dtsch Arztebl Int 2008; 105(23): 397-403 DOI: 10.3238/arztebl.2008.0397

Key words: depression, respiratory insufficiency, amyotrophic lateral sclerosis, assisted suicide, quality of life

Abteilung Neurologie, Universität UIm: Dr. rer. nat. Lulé, Prof. Dr. med. Ludolph Institut für Medizinische Psychologie und Verhaltensneurobiologie, EberhardKarls-Universität Tübingen: Dr. rer. nat. Lulé, Dipl.-Psych. Häcker, Prof. Dr. phil. Birbaumer, PD Dr. rer. nat. Kübler

National Institutes of Health (NIH), NINDS, Human Cortical Physiology, Section Bethesda, USA: Prof. Dr. phil. Birbaumer

Clinical and Health Psychology Research Centre, School of Human and Life Sciences, Roehampton University, London, UK: PD Dr. rer. nat. Kübler onversations with patients and their relatives, physicians, and nurses reveal that these other persons often possess no accurate knowledge of the actual emotional situation of patients with severe impairment of motor function in general, or, more specifically, of patients with amyotrophic lateral sclerosis (ALS, or Lou Gehrig's disease). Ganzini and Block (1) suspect that this is due to a psychological defense mechanism: healthy people have difficulty imagining the feelings and experiences of a severely impaired patient. They generally assume that the patient's quality of life is poor (2). Despite this lack of sure knowledge, however, decisions about life-terminating measures are often made, or at least strongly influenced, by physicians and relatives $(3,4)$. Evidence suggests that, in the Netherlands today, one in five ALS patients dies either by euthanasia or by assisted suicide (5). In Germany, too, there are increasingly loud calls for a liberalization of the law regarding active euthanasia, particularly as it applies to ALS patients in the terminal stage, in order to shorten what is considered to be a period of suffering (e1). A study of the actual quality of life and affective state of ALS patients thus seems to be urgently necessary. The object of the present investigation was to find out whether ALS patients suffer from depressive mood disorders, and whether their quality of life becomes poorer over the course of their illness. The test results of ALS patients were compared with those of normal control subjects and those of other groups of patients without any severe motor impairment. This study is intended to shed light on the question of what life with a severe motor impairment is actually like.

\section{Methods}

In the first segment of the study (I), ALS patients in all stages of the disease were investigated with respect to their affective state (depressive symptoms) and subjectively experienced quality of life (SQL) at the time points T1 and T2 (T2 was 80 to 100 days after T1 for each patient; 39 patients were evaluated at T1, 30 at T2). Possible depressive symptoms were registered with the ALS Depression Inventory (ADI-12) $(6,7)$, an instrument for measuring the patient's self-reported affective state. The possible values on this scale range from 12 (no evidence of depressive symptoms) to 48 (most severe depression possible); values above 28 correspond to clinically relevant depressive symptoms 
TABLE 1

Overview of ALS patients' results from the first segment of this study (T1 and T2) compared with the results of other published studies

\begin{tabular}{|c|c|c|c|c|c|c|}
\hline Study & Patient group & n & & Mean & SD & Range \\
\hline \multirow[t]{3}{*}{ T1 } & $\begin{array}{l}\text { ALS patients } \\
19 \text { women, } 20 \text { men } \\
13 \text { NIV, } 4 \text { IV, } 22 \text { not ventilated }\end{array}$ & 39 & $\begin{array}{l}\text { ALSFRS } \\
\text { Months after diagnosis } \\
\text { Education (years of school) }\end{array}$ & $\begin{array}{l}19.9 \\
43.9 \\
10.80\end{array}$ & $\begin{array}{l}21.1 \\
37.5 \\
1.71\end{array}$ & $\begin{array}{l}0-39 \\
0-170 \\
9-13\end{array}$ \\
\hline & & $\begin{array}{l}11 / 39 \\
28 / 39\end{array}$ & $\begin{array}{l}\text { Depressive symptoms (ADI): } \\
\text { Clinically relevant } \\
\text { Clinically irrelevant }\end{array}$ & 23.85 & 7.13 & $12-42$ \\
\hline & & $\begin{array}{l}17 / 39 \\
22 / 39\end{array}$ & $\begin{array}{l}\text { SQL }(\text { SIS) } \\
\text { Ventilated* } \\
\text { Not ventilated }\end{array}$ & $\begin{array}{l}71.6 \% \\
75.33 \% \\
68.85 \%\end{array}$ & $\begin{array}{l}15.8 \% \\
15.35 \% \\
16.51 \%\end{array}$ & $23-100 \%$ \\
\hline \multirow[t]{2}{*}{ T2 } & $\begin{array}{l}\text { ALS patients } 90 \pm 10 \text { days } \\
\text { after T1 } \\
16 \text { women, } 14 \text { men } \\
10 \text { NIV } 3 \text { IV, } 17 \text { not ventilated }\end{array}$ & 30 & $\begin{array}{l}\text { ALSFRS } \\
\text { Months after diagnosis }\end{array}$ & $\begin{array}{l}17.2 \\
40.5\end{array}$ & $\begin{array}{l}9.7 \\
30.8\end{array}$ & $\begin{array}{l}0-37 \\
4-130\end{array}$ \\
\hline & & $\begin{array}{l}13 / 30 \\
17 / 30\end{array}$ & $\begin{array}{l}\text { SQL }(\mathrm{SIS}) \\
\text { Ventilated* } \\
\text { Not ventilated }\end{array}$ & $\begin{array}{l}69.90 \% \\
77.36 \% \\
64.18 \%\end{array}$ & $\begin{array}{l}17.30 \% \\
18.0 \% \\
14.77 \%\end{array}$ & $26-96 \%$ \\
\hline $\begin{array}{l}\text { Literature } \\
\text { a.) }(e 4) \\
\text { b.) (e5) }\end{array}$ & $\begin{array}{l}\text { Patients with non-fatal } \\
\text { diagnoses: } \\
\text { Irritable bowel syndrome } \\
\text { Chronic gastric ulcer } \\
\text { Diabetes mellitus }\end{array}$ & $\begin{array}{l}120 \\
20 / 120 \\
20 / 120 \\
80 / 120\end{array}$ & SQL (SIS) & $\begin{array}{l}68.6-75.3 \% \\
68.6 \% \\
74.0 \% \\
75.3 \%\end{array}$ & $\begin{array}{l}12.4-12.7 \% \\
12.7 \% \\
12.4 \% \\
\text { N/A }\end{array}$ & $\begin{array}{l}35-96 \% \\
51-94 \% \\
\text { N/A }\end{array}$ \\
\hline
\end{tabular}

* artificially ventilated with intermittent mask ventilation (non-invasive ventilaton, NIV) and invasive ventilation (IV) ALSFRS, limitations of function as assessed with the ALS Functional Rating Scale;

ADI, depressive symptoms (DS) as assessed with the ADI-12 (clinically relevant with ADI-12 scores above 28 , not clinically relevant with ADI-12 scores of 28 or less); SQL, subjective quality of life (measured with the SEIQOL-DW and reported as the SEIQOL index score in \%; SIS is the product of the satisfaction parameter and the personal weighting of the area determining the individual patient's quality of life); SD, standard deviation; N/A, data not available

(DS). The SQL was assessed with the aid of the Schedule for the Evaluation of Individual Quality of Life - Direct Weighting (SEIQoL-DW). The proband is asked to name five specific areas which have an influence on his or her quality of life (no $=0$, yes $=1$ ), and then to assign a weighting, in percent, to each of the areas that were stated to influence the quality of life and to rate his or her satisfaction in each of the five areas on a sevenpoint scale (again expressed in percent). On the basis of these data, the SEIQoL Index Score (SIS) is calculated $(\mathrm{e} 2,8)$ (see additional information in the $e$-supplement). Furthermore, functional impairments were assessed with the ALS Functional Rating Scale (ALSFRS) (e3), ranging from 0 (locked-in state) to 40 (no functional impairment). For the purposes of this article, an ALSFRS score above 15 is considered to correspond to a mild or moderately severe physical impairment, while a score of 15 or below is considered to correspond to a severe impairment. Furthermore, information was obtained about how many years the patient attended school and the time elapsed since the diagnosis (table 1). In a second segment of the study (II), another group of ALS patients was compared to normal control subjects with respect to their subjectively experienced quality of life (SQL), as assessed with the SEIQoL-DW (e2). These patients' functional impairments were registered with the ALSFRS, and data were collected on the time elapsed since their diagnosis.

\section{Statistical analysis}

Pearson correlations were calculated to test the linear correlation between depressive symptoms (ADI-12, metric) and the metric scales of functional impairment (ALSFRS), the time elapsed since diagnosis, the patient's highest educational attainment, and the quality of life (SIS).

A chi-square test was performed to detect any significant differences between the two groups in the frequencies of observed characteristics (i.e., identification of areas with an important influence on life quality) as assessed by the documentation of two independent variables, which were considered dichotomous (DS clinically relevant when ADI-12 >28, no clinically relevant DS when ADI- $12 \leq 28$; mild to moderate physical impairment when ALSFRS >15, severe physical impairment when ALSFRS $\leq 15$ ).

Differences between two independent variables with respect to a dependent variable were tested for significance with Student's t test. Group differences in the information supplied about quality of life (SIS) with respect to the intersubject factor "ventilation group" (ventilated or non-ventilated) were evaluated in this way. On the other hand, differences among several independent variables with respect to a single dependent variable were tested for significance with univariate variance analysis. Group differences in the information supplied about quality of life (SIS, identification and 
satisfaction ratings of determinants of life quality) with respect to the intersubject factor "ALS patients vs. normal controls" were evaluated in this way.

The statistical analysis was performed with SPSS (Statistical Package for the Social Sciences) for Windows, version 14.0. The significance level was tested with two tails and at $p=0.05$. The strength of effects was rated with $\eta^{2}$. The data were analyzed both exploratively and in hypothesis-guided fashion (independence of depression/SQL and physical impairment).

\section{Results}

Study l: emotional state and quality of life of ALS patients over the course of the illness

Self-reported emotional state - $28 \%$ of the ALS patients (T1 11/39) had clinically relevant depressive symptoms (ADI-12 >28) (table 1).

Interactions of the self-reported emotional state - At time T1, ALS patients displayed no correlation between their depressive symptoms (ADI-12) and the extent of their physical impairment (ALSFRS: $r=-0.017$, $\mathrm{p}=0.920$ ) (figure 1) or the time elapsed since diagnosis (months: $\mathrm{r}=0.18, \mathrm{p}=0.267$ ).

In ALS patients (T1), depressive symptoms (ADI-12) were significantly correlated with shorter schooling $(\mathrm{r}=-0.41, \mathrm{p}=0.005)$.

Subjectively experienced quality of life (SQL), SIS ALS patients reported, both at time T1 and at time T2, that they were experiencing a quality of life comparable to that reported by other chronically ill patients without severe motor impairment (SIS; no quantitative comparison is possible here because of a lack of original data in the literature) (e4, e5) (table 1).

Patient-reported determinants of SQL-ALS patients with DS (T1 11/39 ADI-12 >28) named health (9/11, $\left.\chi^{2}=6.72, p=0.010, \eta^{2}=0.42\right)$ and mobility $(6 / 11$, $\left.\chi^{2}=4.07, \mathrm{p}=0.044, \eta^{2}=0.32\right)$ as areas determining their quality of life significantly more commonly than did ALS patients without DS (T1 28/39 ADI-12 = 28; health named by $10 / 28$, mobility by $6 / 28$ ). ALS patients without DS were significantly more likely to name personal well-being as a determinant of their quality of life $\left(8 / 28, \chi^{2}=3.95, p=0.047, \eta^{2}=0.32\right)($ table 2$)$; no ALS patient with DS did so.

Markedly physically impaired ALS patients (T1 $16 / 39$ ALSFRS $\leq 15)$ named communication (7/16, $\left.\chi^{2}=5.93, p=0.029, \eta^{2}=0.39\right)$ and medical care $\left(10 / 16, \chi^{2}=9.36, p=0.002, \eta^{2}=0.49\right)$ as areas determining their quality of life significantly more commonly than did patients with only mild or moderately severe impairment (T1 23/39 ALSFRS >15; communication named by $0 / 23$, medical care named by $0 / 23$ ).

Interactions of the subjectively experienced quality of life (SQL) - In ALS patients (T1), there was a significant negative correlation of the SQL (SIS) with ADI-12 depression scores (ADI-12; $r=-0.36, p=0.027$ ). The lower the depression score, the higher the quality of life.

ALS patients were found, over the course of the disease (T2), to develop a significant correlation between

\section{FIGURE 1}

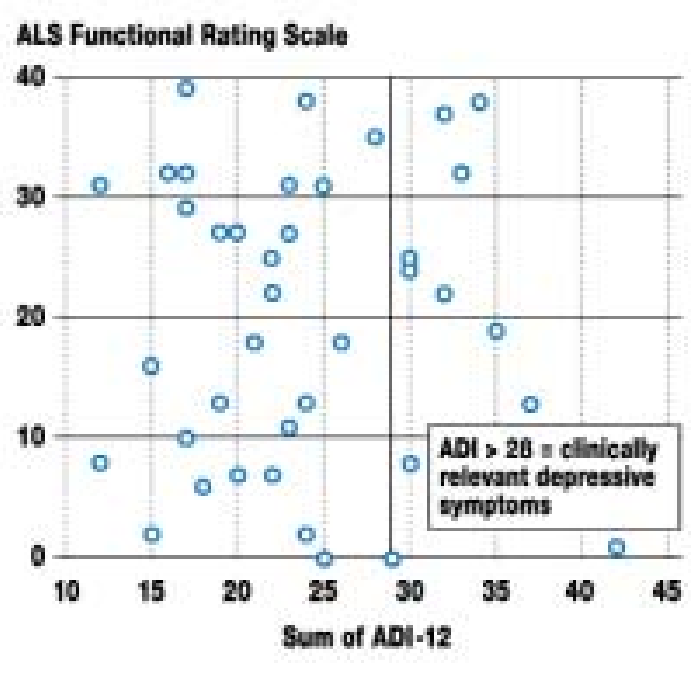

Scatter plot of depressive symptoms (as measured with the ALS Depression Inventory, ADI-12 [Kübler et al., 2005; Hammer et al. 2008], T1) and physical impairment (as measured with the ALS Functional Rating Scale, ALSFRS) in ALS patients ( $T 1, n=39)$. There is no correlation between the two parameters $(r=-0.17$, $p=0.97)$. ADI scores above 28 indicate clinically relevant depressive symptoms. This was the case for 11 of the 39 patients in this study $(28 \%)$.

the subjectively experienced quality of life (SIS) and the extent of their physical impairment (ALSFRS; $\mathrm{r}=-0.43, \mathrm{p}=0.021)$. The sign of the correlation was, however, negative: the more severe the physical impairment was, the better the subjectively experienced quality of life.

Ventilated patients (T1; invasively and non-invasively ventilated patients, 17/39; SIS) showed no significant differences in SQL to non-ventilated patients (22/39; SIS; $\mathrm{t}=-0.75, \mathrm{p}=0.461)$. Over the course of the disease (T2), ventilated patients (13/30; SIS) had a significantly higher subjectively experienced quality of life than nonventilated ALS patients (17/30; SIS; $t=2.20$, $\mathrm{p}=0.035$ ).

\section{Study II: the quality of life of ALS patients compared with that of} normal controls

Subjectively experienced quality of life (SQL), SIS In the second segment of the study (II), which involved a different group of ALS patients with mild to moderately severe physical impairment compared to normal control subjects, no statistically significant difference in quality of life was found between these two groups (SIS, variance test variable $\mathrm{F}=0.11, \mathrm{p}=0.745, \eta^{2}<0.01$ ) (table 3).

Patient-reported determinants of the subjectively experienced quality of life-ALS patients (II) were significantly more likely to name friends and social environment as determinants of their quality of life than were the normal control subjects (for naming: $\mathrm{F}=4.03$, 
TABLE 2

Patient-reported determinants of the quality of life in ALS patients with and without depressive symptoms (study l)

\begin{tabular}{|l|l|l|l|l|l|}
\hline $\begin{array}{l}\text { Reported determinants } \\
\text { of SQL }\end{array}$ & ALS patients with DS (\%) & ALS patients without DS (\%) & $\chi^{2}$ & $p$ & $\eta^{2}$ \\
\hline Health & $82(9 / 11)$ & $36(10 / 28)$ & 6.7 & 0.01 & 0.42 \\
\hline Mobility & $55(6 / 11)$ & $21(6 / 28)$ & 4.1 & 0.04 & 0.32 \\
\hline Personal well-being & 0 & $29(8 / 28)$ & 3.9 & 0.05 & 0.32 \\
\hline
\end{tabular}

Data displayed for three factors that were named as being important for the quality of life (as measured with SEIQoL) The number of factors named as being important varied significantly between ALS patients with clinically relevant depressive symptoms (DS; ADI-12 score > 28; 11/39 patients) and ALS patients without clinically relevant depressive symptoms (ADI-12 score $\leq 28 ; 28 / 39$ patients). $\chi^{2}$, statistical variable relating to the possible correlation of depressive symptoms with the naming of particular factors; $\mathrm{p}$, variable relating to statistical significance; $\eta^{2}$, variable indicating the degree to which each individual factor contributes to the total variance

\section{TABLE 3}

\section{Overview of descriptive statistics (study II)}

\begin{tabular}{|l|l|l|l|l|l|l|}
\hline Study & Patient group & $\mathbf{n}$ & & Mean & SD & Range \\
\hline II & ALS Patients & \multirow{2}{*}{30} & ALSFRS & 28.2 & 11.6 & $7-36$ \\
& 16 women, 14 men; & & Months since diagnosis & 40.8 & 18.0 & $1-60$ \\
& 14 NIV, 0 IV, 15 not ventilated & & Education (years of school) & 10.3 & 2.8 & $9-13$ \\
& & SQL (SIS) & $65.7 \%$ & $13.0 \%$ & $37.9-90.2 \%$ \\
& \multirow{2}{*}{$\begin{array}{l}\text { Normal control subjects } \\
\text { 16 women, 14 men }\end{array}$} & \multirow{2}{*}{30} & Education (years of school) & 10.7 & 3.1 & $9-13$ \\
& & SQL (SIS) & $64.7 \%$ & $10.2 \%$ & $42.4-88.5 \%$ \\
\hline
\end{tabular}

Overview of findings in ALS patients and normal control subjects in the second segment of the study (III). ALSFRS, limitations of function as assessed with the ALS Functional Rating Scale; NIV, intermittent mask ventilation (non-invasive ventilation); IV, invasive ventilation; SQL, subjective quality of life (measured with the SEIQOL-DW and reported as the SEIQOL index score in \%; $\mathrm{SIS}$ is the product of the satisfaction parameter and the personal weighting of the area determining the individual patient's quality of life); $\mathrm{SD}$, standard deviation

$\left.\mathrm{p}=0.050, \eta^{2}=0.07\right)$ (table 4) but significantly less likely to name their occupation or financial status (for naming: $F=8.29, p=0.006, \eta^{2}=0.12$ ). ALS patients were significantly more satisfied with the area "family" than the normal control subjects (satisfaction: $\mathrm{F}=16.78, \mathrm{p}<0.001, \eta^{2}=0.26$ ), although ALS patients were significantly less satisfied with their health than the normal control subjects (satisfaction: $F=8.79$, $\left.\mathrm{p}=0.005, \eta^{2}=0.18\right)$.

\section{Discussion \\ ALS and emotional state}

The prevalence of depressive symptoms in patients with ALS has been reported with a great deal of variability among studies, with values ranging from $0 \%$ (9) to $44 \%$ $(10$, e6). In the present study, $28 \%$ of patients with ALS had clinically relevant depressive symptoms; this figure is consistent with rates reported in the majority of the other studies (mid-range values, $24 \%$ to $28 \%$ (11-13). The few studies in which depression was diagnosed by means of a DSM-IV structured clinical interview (e7) consistently showed prevalences in the range of $9 \%$ to $11 \%$ (11-14) (this corresponds to the $11 \%$ value that we found in the same ALS patients that constituted the T1 group in the present study [7]). Thus, the prevalence of DSM-IV-defined depression is slightly higher among
ALS patients than in the general population (4\% to 5\%) (e8), yet lower than among patients with multiple sclerosis $(17 \%$ to $46 \%)$ (e9, e10). The discrepancies among the different prevalences of depression among ALS patients that were reported in different studies is attributable, among other things, to the fact that the clinical interview according to DSM-IV registers not only the patient's momentary affective state, but also any history of earlier depressive episodes that occurred prior to the diagnosis ALS; the ADI-12, on the other hand, which we used as a screening test in the present study, measures the self-reported momentary affective state and is therefore less specific and generally yields markedly higher rates of depression.

In our study, we found no correlation between depressive symptoms and the extent of physical impairment, or the time since diagnosis, in patients with ALS. The same has been shown in other studies $(6,12$, 15-17). For carcinoma patients, however, an association between depressive symptoms and the extent of physical impairment has been observed (e11). A significant correlation was found between the educational level of ALS patients and the severity of their depressive symptoms; the more years the patients had spent in school, the lower their depression scores. A possible reason for this correlation is the greater ability of better educated 
persons to develop functional coping strategies. The observed lack of a rise in the depression rate as the functional impairment worsens and the elapsed time from the diagnosis of the illness lengthens refutes the commonly voiced notion that emotional stress and depressive mood must necessarily become worse as the physical disease progresses. The fact is that depressive episodes can occur in any stage of ALS and be amenable to pharmacological and psychotherapeutic treatment (18). There is no empirical basis for the fatalistically postulated correlation of ALS with depression (12).

\section{ALS and the quality of life}

In multiple studies, ALS patients have reported experiencing a sometimes quite surprisingly high subjective quality of life despite their marked physical impairment $(6,12)$. In the present study, too, the mean subjective quality of life among ALS patients was in the range of $66 \%$ to $72 \%$ and thus comparable to that of normal control subjects. Few or no correlations were found between these patients' subjective quality of life and their degree of physical impairment or the length of time elapsed since the diagnosis was made $(7,12,15,16,17$, 19). In the present study, in fact, the subjective quality of life actually rose over time as the patients' physical impairment worsened. Ventilated patients had a better SQL than non-ventilated ALS patients. This may be explained as a result of the beneficial symptomatic effects of ventilation, including lessening daytime fatigue. Our data suggest that even patients in an advanced stage of ALS can subjectively experience a high quality of life.

The subjective quality of life of ALS patients in our studies lay in a range comparable to that of chronically ill patients without any severe motor impairment, as determined in a number of other studies (SQL ca. 70\%) (e4, e12, e13). In contrast, carcinoma patients in an advanced stage of disease attain SQL values $(<60 \%)$ $(20$, e14) that are significantly lower than those of ALS patients when directly compared with them (20) and that continue to decline as the disease produces progressive physical impairment (e11, e15).

These data permit the conclusion that ALS patients, compared to patients with other diseases that do not regularly produce severe paralysis (figure 2), may surprisingly enjoy a subjectively experienced quality of life that is comparable or significantly higher. At present, we can only speculate on the possible causes of this special position of ALS patients relative to others.

Among the ALS patients in this study, depression was associated with a negative subjective quality of life, confirming the well-known close relationship of the affective state and the quality of life (6). Depressed ALS patients seem to define their quality of life to a greater extent as a function of external experiences that are no longer accessible to them, such as health and mobility. For nondepressed ALS patients, on the other hand, internal areas such as personal well-being seem to be more important. These areas can remain intact even as the disease progresses.

In accordance with the data presented here, Neudert et al. have confirmed that ALS patients shift their priorities
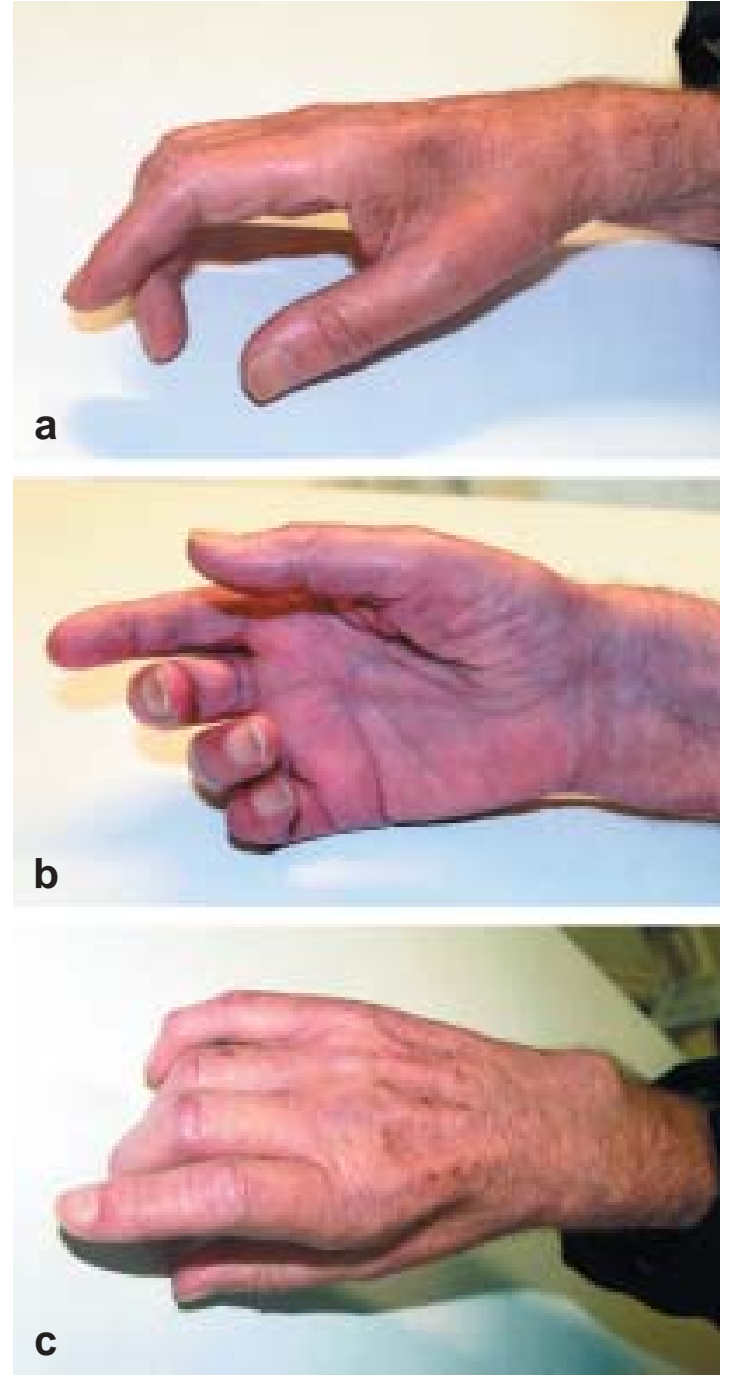

Figure 2 a-c: Amyotrophic lateral sclerosis (ALS) a very severe neurological illness, is characterized by rapidly progressive paralysis of the skeletal muscles (the intrinsic muscles of the hand are shown here), specifically including the muscles of swallowing and respiration. with respect to quality of life to center them more on social aspects (8). In our study, ALS patients named their friends and social environment as determinants of their quality of life significantly more often than their occupation and financial status. Moreover, they were significantly more satisfied with their families. As ALS progressed, certain areas became increasingly important for these patients' subjective quality of life while the physical impairment worsened. Severely impaired ALS patients named communication and medical care significantly more often as determinants of the quality of life than did mildly to moderately impaired patients, who, in fact, did not name these areas at all. These data suggest that ALS patients develop successful adaptive strategies with respect to the needs and priorities corresponding to their living conditions in each stage of the disease.

Some possible limitations of the present study might include a lack of representativeness of the populations and the small sample sizes in the two different segments of the study (I and II). Questioning of very severely physically impaired patients can hardly be performed on 
TABLE 4

Patient-reported satisfaction with various factors determining the quality of life in ALS patients compared to normal control subjects (study II)

\begin{tabular}{|c|c|c|c|c|c|c|c|}
\hline & & Mean & SD & Range & $\mathbf{F}$ & $\mathbf{p}$ & $\eta^{2}$ \\
\hline Friends/social sphere & $\begin{array}{l}\text { ALS patients } \\
\text { Normal controls }\end{array}$ & $\begin{array}{l}0.73 \\
0.48\end{array}$ & $\begin{array}{l}0.45 \\
0.51\end{array}$ & $\begin{array}{l}0-1^{* 1} \\
0-1^{* 1}\end{array}$ & 4.03 & 0.05 & 0.07 \\
\hline Occupation/finances & $\begin{array}{l}\text { ALS patients } \\
\text { Normal controls }\end{array}$ & $\begin{array}{l}0.50 \\
0.83\end{array}$ & $\begin{array}{l}0.51 \\
0.38\end{array}$ & $\begin{array}{l}0-1^{* 1} \\
0-1^{* 1}\end{array}$ & 8.29 & 0.01 & 0.12 \\
\hline Family & $\begin{array}{l}\text { ALS patients } \\
\text { Normal controls }\end{array}$ & $\begin{array}{l}84.01 \% \\
71.13 \%\end{array}$ & $\begin{array}{l}11.72 \% \\
10.28 \%\end{array}$ & $\begin{array}{l}66.8-100 \% * 2 \\
66.8-100 \%{ }^{* 2}\end{array}$ & 16.78 & 0.00 & 0.26 \\
\hline Health & $\begin{array}{l}\text { ALS patients } \\
\text { Normal controls }\end{array}$ & $\begin{array}{l}38.94 \% \\
54.93 \%\end{array}$ & $\begin{array}{l}18.97 \% \\
15.93 \%\end{array}$ & $\begin{array}{l}16.7-83.4 \% * 2 \\
33.4-83.4 \% * 2\end{array}$ & 8.79 & 0.00 & 0.18 \\
\hline
\end{tabular}

Comparison of patients' reports on their subjectively experienced quality of life (measured with the SEIQOL-DW) in ALS patients (study segment II) compared to normal control subjects. SD, standard deviation.

*1, 0 , factor not named as an important determinant of the quality of life; 1 , factor named as an important determinant of the quality of life; ${ }^{*}$, The degree of satisfaction in each area was rated on a seven-point scale ranging from $0(0 \%)=$ "could not be worse" to $100(100 \%)=$ "could not be better."

much larger study populations than these. Patients lacking contact to the outpatient ALS clinic were presumably underrepresented in this study, as were patients lacking the interest to participate. Despite these qualifications, the surprising finding remains that neither the subjective quality of life nor depression is correlated to any significant extent with the patient's physical impairment. The studies presented here and the related findings reported in the literature have implications for the management of patients with ALS, including with respect to the euthanasia debate.

\section{Conclusion}

The results reported here with respect to the subjective quality of life and depressive symptoms in ALS patients in both the earlier and the later stages of the disease contradict the widespread opinion that patients with severe physical impairment necessarily suffer to an extreme degree. The decision not to undergo life-prolonging treatment is due to the fear of loss of autonomy and control and to the worry that a lack of mobility and impaired communication will lead to social isolation (1). Moreover, it is often assumed that severely paralyzed patients have a low quality of life, particularly when they are dependent on life-sustaining treatment (2). The fact that ventilated ALS patients reported enjoying a significantly higher quality of life than non-ventilated ones contradicts this notion as well. Many useful therapeutic measures are available, including invasive ventilation and communication devices that give the patient a greater measure of autonomy, improving the quality of life (e17, e18) by generating a feeling of control over one's own fate (e16). It seems likely that information is often inadequately communicated and the available treatment modalities are often underutilized (1). Depression usually goes untreated $(12,14)$, because it is viewed as a normal accompaniment of a fatal illness. If the results of this study were to be thoroughly discussed with ALS patients and their families, and if all therapeutic options were to be presented to them, including the possibility of cessation of invasive ventilation and artificial feeding, it may be that more patients would opt to continue treatment than is currently the case $(21,26$, e16). It can be assumed that excellent palliative care would markedly reduce the number of requests for an accelerated death $(1,23)$.

The authors hope that these empirical data on the emotional state of severely impaired patients will serve as firmer scientific ground for future discussions of physician-assisted suicide (PAS), and that they will pave the way for further studies that share the goal of putting the emphasis on the patient's perspective.

\section{Conflict of interest statement}

The authors declare that no conflict of interest exists as defined by the guidelines of the International Committee of Medical Journal Editors.

\section{Informed Consent and Ethical Approval}

The research subjects participating in these studies consented in writing to their participation. The studies were approved by the Ethics Committees of the Universities of UIm and Tübingen.

\section{Acknowledgements}

We thank Ertan Altintas (II, questioning of ALS patients; University of UIm), Eva-Maria Braun (I), and Claudia Zickler (IT2, questioning of ALS patients; University of Tübingen) for their support in patient recruiting, data acquisition, and data analysis.

Manuscript received on 6 July 2007; revised version accepted on 18 April 2008

Translated from the original German by Ethan Taub, M.D.

\section{REFERENCES}

1. Ganzini L, Block S: Physician-assisted death - a last resort? N Engl J Med 2002; 346: 1663-5.

2. McDonald ER, Hillel A, Wiedenfeld SA: Evaluation of the psychological status of ventilatory-supported patients with ALS/MND. Palliat Med 1996; 10: 35-41.

3. Moss AH, Casey P, Stocking CB, Roos RP, Brooks BR, Siegler M: Home ventilation for amyotrophic lateral sclerosis patients: outcomes, costs, and patient, family, and physician attitudes. Neurology 1993; 43: 438-43.

4. Borasio GD, Voltz R: Discontinuation of mechanical ventilation in patients with amyotrophic lateral sclerosis. J Neurol 1998; 245: $717-22$ 
5. Veldink JH, Wokke JH, van der Wal G, Vianney de Jong JM, van den Berg LH: Euthanasia and physician-assisted suicide among patients with amyotrophic lateral sclerosis in the Netherlands. N Engl J Med 2002; 346: 1638-44.

6. Kubler A, Winter S, Ludolph AC, Hautzinger M, Birbaumer N: Severity of depressive symptoms and quality of life in patients with amyotrophic lateral sclerosis. Neurorehabil Neural Repair 2005; 19: 182-93

7. Hammer EM, Häcker S, Hautzinger M, Meyer TD, Kübler A: Validity of the ALS-Depression-Inventory (ADI-12) - A new screening instrument for depressive disorders in patients with amyotrophic lateral sclerosis. J Affect Disord 2008 Feb 7 (Epub ahead of print).

8. Neudert C, Wasner M, Borasio GD: Patients' assessment of quality of life instruments: a randomized study of SIP, SF-36 and SEIQDL-DW in patients with amyotrophic lateral sclerosis. J Neurol Sci 2001; 191: 103-9.

9. Bungener C, Piquard A, Pradat PF, Salachas F, Meininger V, Lacomblez L: Psychopathology in amyotrophic lateral sclerosis: a preliminary study with 27 ALS patients. Amyotroph Lateral Scler Other Motor Neuron Disord 2005; 6: 221-5.

10. Lou JS, Reeves A, Benice T, Sexton G: Fatigue and depression are associated with poor quality of life in ALS. Neurology 2003; 60: 122-3.

11. Ganzini L, Johnston WS, Hoffman WF: Correlates of suffering in amyotrophic lateral sclerosis. Neurology 1999; 52: 1434-40.

12. Rabkin JG, Wagner GJ, Del Bene M: Resilience and distress among amyotrophic lateral sclerosis patients and caregivers. Psychosom Med 2000; 62: 271-9.

13. Rabkin JG, Albert SM, Del Bene ML et al.: Prevalence of depressive disorders and change over time in late-stage ALS. Neurology 2005; 65: 62-7.

14. Kurt A, Nijboer F, Matuz T, Kubler A: Depression and anxiety in individuals with amyotrophic lateral sclerosis: epidemiology and management. CNS Drugs 2007; 21: 279-91.

15. Robbins RA, Simmons Z, Bremer BA, Walsh SM, Fischer S: Quality of life in ALS is maintained as physical function declines. Neurology 2001; 56: 442-4.

16. Simmons Z, Bremer BA, Robbins RA, Walsh SM, Fischer S: Quality of life in ALS depends on factors other than strength and physical function. Neurology 2000; 55: 388-92.
17. Simmons Z: Management strategies for patients with amyotrophic lateral sclerosis from diagnosis through death. The Neurologist 2005; 11: 257-70

18. Goldstein LH, Atkins L, Landau S, Brown RG, Leigh PN: Longitudinal predictors of psychological distress and self-esteem in people with ALS. Neurology 2006; 67: 1652-8.

19. Neudert C, Wasner M, Borasio GD: Individual quality of life is not correlated with health-related quality of life or physical function in patients with amyotrophic lateral sclerosis. J Palliat Med 2004; 7: $551-7$.

20. Fegg MJ, Wasner M, Neudert C, Borasio GD: Personal values and individual quality of life in palliative care patients. J Pain Symptom Manage 2005; 30: 154-9.

21. Albert SM, Rabkin JG, Del Bene ML et al.: Wish to die in endstage ALS. Neurology 2005; 65: 68-74.

22. Quill T: Highlights and Commentary: ALS, depression, and desire for a hastened death: (how) are they related? Neurology 2005; 65: 1.

23. Bascom PB, Tolle SW: Responding to requests for physicianassisted suicide: „These are uncharted waters for both of us ...". JAMA 2002; 288: 91-8.

24. Kühnlein $P$, Kübler $A$, Raubold $S$ et al.: Palliative care and circumstances of dying in German ALS patients using non-invasive ventilation. Amyotroph Lateral Scler. (In press).

25. Hecht M, Hillemacher T, Grasel E et al.: Subjective experience and coping in ALS. Amyotroph Lateral Scler Other Motor Neuron Disord 2002; 3: 225-31.

\section{Corresponding author}

Prof. Dr. med. Albert Ludolph

Neurologische Klinik der Universität Ulm im

Rehabilitationskrankenhaus UIm (RKU)

Oberer Eselsberg 45

89081 Ulm, Germany

albert.ludolph@rku.de

For e-references please see:

www.aerzteblatt-international.de/ref2308

e-supplement:

www.aerzteblatt-international.de/article08m397 


\title{
Depression and Quality of Life in Patients With Amyotrophic Lateral Sclerosis
}

\author{
Dorothée Lulé, Sonja Häcker, Albert Ludolph, Niels Birbaumer, Andrea Kübler
}

\section{E-REFERENCES}

e1. Beschluss zu „Patientenautonomie und Strafrecht bei der Sterbebegleitung". 66. Deutscher Juristentag 2006 in Stuttgart, http://www.djt.de/index.php. abgerufen am 12.11.2007.

e2. O'Boyle CA, Browne J, Hickey A, McGee H, Joyce CRB: Manual for the SEIQoL-DW. Dublin, Department of Psychology, Royal College of Surgeons in Ireland, 1996.

e3. Cedarbaum JM, Stambler N, Malta E et al.: The ALSFRS-R: a revised ALS functional rating scale that incorporates assessments of respiratory function. BDNF ALS Study Group (Phase III). J Neurol Sci 1999; 169: 13-21.

e4. McGee HM, O'Boyle CA, Hickey A, O'Malley K, Joyce CR: Assessing the quality of life of the individual: the SEIQoL with a healthy and a gastroenterology unit population. Psychol Med 1991; 21: 749-59.

e5. Walker J, Bradley C: Assessing the quality of life of adolescents with diabetes: using the SEIQoL, DQOL, patient and diabetes specialist nurse ratings. Pract Diab Int 2002; 19: 141-4.

e6. Hogg KE, Goldstein LH, Leigh PN: The psychological impact of motor neurone disease. Psychol Med 1994; 24: 625-32.

e7. Wittchen H-U, Zaudig M, Fydrich M: Strukturiertes Klinisches Interview für DSM-IV (SKID), Achse I. Göttingen, Hogrefe 1997.

e8. Narrow WE, Rae DS, Robins LN, Regier DA. Revized prevalence estimates of mental disorders in the United States: using a clinical significance criterion to reconcile 2 surveys' estimates. Arch Gen Psychiatry 2002; 59: 115-23.

e9. Feinstein A, Feinstein K: Depression associated with multiple sclerosis. Looking beyond diagnosis to symptom expression. J Affect Disord 2001; 66: 193-8

e10. Galeazzi GM, Ferrari S, Giaroli G et al.: Psychiatric disorders and depression in multiple sclerosis outpatients: impact of disability and interferon beta therapy. Neurol Sci 2005; 26: 255-62.

e11. Frick E, Tyroller M, Panzer M: Anxiety, depression and quality of life of cancer patients undergoing radiation therapy: a cross-sectional study in a community hospital outpatient centre. Eur J Cancer Care 2007; 16: 130-6. e12. Carlson LE, Bultz BD, Morris DG: Individualized quality of life, standardized quality of life, and distress in patients undergoing a phase-I-trial of the novel therapeutic Reolysin (reovirus). Health and Quality of Life Outcomes 2005; 3: 7.

e13. Moons P, Marquet K, Budts W, De Geest S: Validity, reliability and responsiveness of the „Schedule for the Evaluation of Individual Quality of Life - Direct Weighting" (SEIQoL-DW) in congenital heart disease. Health and Quality of Life Outcomes 2004; 2: 27.

e14. Waldron D, O'Boyle CA, Kearney M, Moriarty M, Carney D: Qualityof-life measurement in advanced cancer: assessing the individual. J Clin Oncol 1999: 17: 3603-11.

e15. Jenewein J, Zwahlen RA, Zwahlen D, Drabe N, Moergeli H, Büchi S Quality of life and dyadic adjustment in oral cancer patients and their female partners. Eur J Cancer Care 2008; 17: 127-35.

e16. Leeman CP: Physician-assisted death. N Engl J Med 2002; 347 1041-3.

e17. Miller RG, Rosenberg JA, Gelinas DF et al.: Practice parameter: the care of the patient with amyotrophic lateral sclerosis (an evidencebased review): report of the Quality Standards Subcommittee of the American Academy of Neurology: ALS Practice Parameters Task Force. Neurology 1999; 52: 1311-23.

e18. Voltz R, Borasio GD: Palliative therapy in the terminal stage of neurological disease. J Neurol 1997; 244: 2-10.

e19. Clarke $S$ et al.: Assessing individual quality of life in amyotrophic lateral sclerosis. Qual Life Res 2001; 10(2): 149-59.

e20. O'Boyle CA et al.: The schedule for the evaluation of individual quality of life. User manual. Dublin: Department of Psychology, Royal College of Surgeons in Ireland 1993.

e21. Bortz J: Statistik für Sozialwissenschaftler. Berlin: Springer 1999.

e22. Cohen J: Statistical Power Analysis for the Behavioral Sciences, 2. edition, Hillsdale: Lawrence Erlbaum Associates 1988. 


\title{
Depression and Quality of Life in Patients With Amyotrophic Lateral Sclerosis
}

\author{
Dorothée Lulé, Sonja Häcker, Albert Ludolph, Niels Birbaumer, Andrea Kübler
}

\section{The emotional state of ALS patients over the course of the disease}

\section{Study (T1 and T2)}

Further information on the study can be found in Häcker S: Depressivität und subjektive Lebensqualität bei schwerster körperlicher Beeinträchtigung (diploma thesis, University of Tübingen, 2006).

The questioning of ALS patients was carried out by Sonja Häcker (T1), Eva-Maria Braun (T2), and Claudia Zickler (T2), doctoral candidates in the Department of Medical Psychology and Behavioral Neurology at the University of Tübingen.

\section{Participants}

The categorization of the degree of physical impairment of ALS patients was performed according to the "ALS Functional Rating Scale" (ALSFRS) (e3), in which scores below 15 correspond to mild or moderate impairment and 15 or above to severe impairment. The terms that are used to describe patients' physical functioning in the text of the article can be roughly defined as follows:

- Mild physical impairment = little or no impairment of limb mobility, normal speech

- Moderate physical impairment $=$ severe weakness and normal speech, or impaired speech with intact mobility

- Severe physical impairment = very severe weakness, limited ability to speak

- Locked-in syndrome $=$ the voluntary muscles can no longer be activated, with the exception of the extraocular and possibly also the perioral muscles

- Absolute locked-in state = no voluntary movement of any kind is possible; terminal phase of ALS.

\section{Instruments}

The patient's subjective quality of life (SQL) was assessed by means of the "Schedule for the Evaluation of Individual Quality of Life - Direct Weighting" (SEIQoL-DW), a valid and reliable instrument that strongly emphasizes the subjective perspective. Many traditional instruments for assessing quality of life emphasized physical and health-related determinants, but the subjectively experienced quality of life in ALS is not a function of physical impairment, as has already been shown in a number of studies $(6,12,15,16,19)$. In the present study, therefore, ALS patients' quality of life was assessed exclusively subjectively, i.e., from the patients' own reports about their subjective experiences. The SEIQoL has been found to be valid for the assessment of subjective quality of life in ALS patients (e19).

The SEIQoL consists of a standardized, semistructured interview for the assessment of the individual, i.e., subjectively experienced, quality of life (e20). The SEIQoL-DW is a simplified and more efficient version of the SEIQoL (e2). Because it is easier to apply, it is recommended for use primarily with very severely ill patients (e19).

In the first step of the SEIQoL-DW, the person being tested (proband) names five specific areas which have an influence on his or her quality of life (no $=0$, yes $=1)$. The proband then assigns a weighting, in percent, to each of the areas stated to influence the quality of life. In a further step, the proband is asked to rate his or her satisfaction in each of the five areas on a seven-point scale (again in percent): the seven levels range from "could not be worse" $=0 \%$ to "could not be better" $=100 \%$. On the basis of these data, a SEIQoL Index Score (SIS) is calculated (box).

The rate of depression in ALS patients was studied with the ALS Depression Inventory (ADI-12), a screening instrument developed especially for ALS patients $(6,7)$ that allows them to self-report their level of depression continuously. The ALS patients in the present study (T1) were also given an additional, extensive test lasting about two hours (structured clinical interview according to the Diagnostic and Statistical Manual of Mental Disorders, DSM-IV) (7, e7).

BOX

The SEIQOL index score

$\mathrm{SIS}=\sum_{1}^{5}\left(\frac{\% \text { satisfaction } \times \% \text { weighting }}{100}\right)$

The SEIQoL index score is a measure of the current subjective quality of life. It is expressed as a percentage and is thus a psychometric parameter. 
These results have already been published; thus, the current article does not duplicate this information but instead refers to the earlier publication. Functional impairments (ALSFRS) and demographic data were also registered. Patient questioning for the acquisition of data presented in study I segments $\mathrm{T} 1$ and $\mathrm{T} 2$ (exclusive of the DSM-IV interview) took about one to three hours for each patient.

\section{Investigation of the interaction of social factors and ALS patients' quality of life}

\section{Study II}

Further information may be found in Altintas E: Emotionales Erleben von ALS-Patienten - Einfluss des sozialen Umfeldes (dissertation, University of Ulm, 2008).

The ALS patients and normal control subjects were questioned by Ertan Altintas, doctoral candidate in medicine.

\section{Participants}

A further group of 30 ALS patients and 30 normal control subjects was studied. The two groups were comparable in age (ALS: $59.5 \pm 9.6$ years, control: $58.4 \pm 10.3$ years), in sex (both groups contained 16 women and 14 men), and in the level of education attained (years of school, ALS: $10.27 \pm 2.79$, control: $10.67 \pm 3.13$ ) (table 3 ).

\section{Instruments}

The patients' quality of life was assessed with the SEIQoL-DW. Functional impairments (ALSFRS) and demographic data were also registered. Patient questioning took about two to three hours.

\section{Methods of testing and data interpretation}

The patients were recruited through the ALS ambulatory clinic of the neurology department at the University of Ulm. The tests were performed either at the patient's home or immediately after a scheduled visit to the ambulatory clinic.

The normal control subjects (study segment II) were recruited by posters that were hung up at the University of Ulm. Most of the participants were attendees of the senior citizens' educational programs of the university's Centre for General Scientific Continuing Education (Zentrum für Allgemeine Wissenschaftliche Weiterbildung, ZAWiW). The questioning of the normal control subjects was performed in the University of Ulm's neurology department.

Subjects were excluded from the study because of a known, clinically relevant psychiatric diagnosis, the use of centrally active medications, or clinically relevant cognitive impairment, because all subjects needed to understand the tasks before them as a precondition for participation. The authors took this information from the patients' medical records and from statements of the control subjects themselves (as evaluated by the leader of the study team).

All participants were thoroughly informed about the content and performance of the studies and agreed in writing to their participation. The studies were approved by the local ethics committee of Ulm and Tübingen.

Correlations were interpreted as follows: $r$ in the range 0.20 to 0.30 was considered a weak correlation, 0.4 to 0.5 moderately strong, 0.6 to 0.7 strong, and 0.8 to 1.0 very strong (e21). The strength of an effect was quantified with the $\eta^{2}$ value, on the assumption that values below 0.01 correspond to a weak effect and values above 0.14 to a strong one (e22). 